\title{
Culture Juridique et Politique: Une Introduction
}

\author{
Carlos Miguel Herrera ${ }^{1}$
}

Published online: 18 April 2016

(C) Springer Science+Business Media Dordrecht 2016

Le Dictionnaire de la culture juridique, l'un des meilleurs ouvrages en son genre publié en langue française, revoit dans ses quelques 400 entrées les principales notions de la tradition juridique française et européenne, à l'exception de celle de ... «culture juridique». Moins que de l'ordre de l'évidence, cette absence est peut-être un symptôme d'une difficulté à saisir cette expression, si répandue, théoriquement. ${ }^{1}$

Pourtant, sa proximité avec la pensée juridique est ancienne. Pendant longtemps, le concept de «culture» fut le patrimoine de la Philosophie du droit, notamment de langue allemande, héritage de la discussion épistémologique du dernier quart du $\mathrm{XIX}^{\mathrm{e}}$ siècle. Gustav Radbruch pour ne citer qu'un seul nom, le mettra au centre de sa conception du droit. ${ }^{2}$ Mais depuis les travaux de Lawrence Friedman, dans les

\footnotetext{
${ }^{1}$ [1]. Voir, en revanche [3], où nous trouvons une entrée culture juridique, due aux plumes de Giorgio Rebuffa et E. Blankenburg. Il est cependant impossible d'établir l'inventaire complet d'ouvrages et textes traitant sur la question ces 30 dernières années.

${ }^{2}$ Pour G. Radbruch, le concept du droit se trouve en effet dans l'interrègne de la culture, là où il existe un «rapport aux valeurs»—c'est pourquoi il conçoit la science juridique comme science culturelle. Le droit, qui doit être pensé comme un être, est plus exactement un fait culturel qui, comme structure de l'être, forme le substrat de la valeur justice, lui assurant son effectivité. Le concept de droit est donc un concept culturel dont la réalité a pour sens de servir la valeur du droit, l'idée de droit. La discussion sera particulièrement importante à l'époque dans le droit constitutionnel, chez des auteurs comme Rudolf Smend ou Hermann Heller. La tradition de la science du droit—constitutionnel surtout—comme science culturelle restera très vivace en Allemagne.
}

André-Jean Arnaud: In memoriam.

Carlos Miguel Herrera

carlos.herrera@u-cergy.fr

1 Cergy-Pontoise, France 
années $1970,{ }^{3}$ l'expression «culture juridique» a fait l'objet d'un regain d'intérêt, notamment dans la Sociologie du droit et le Droit comparé. La notion pouvait être même le pont qui reliait ces deux disciplines; c'est ainsi que concluaient des sociologues du droit ayant commis un guide sur la culture juridique hollandaise: «the best method of getting to know one's own culture is to compare with others». ${ }^{4}$ Par rapport aux appropriations précédentes, qui portaient l'accent sur la culture, la notion de «culture juridique» insistait davantage sur la spécificité du phénomène en droit. Mais aussi sur sa pertinence sociale car, d'après Friedman, le concept est vital pour déterminer les circonstances sociales dans lesquelles opère le système juridique, une «variable d'intervention essentielle», comme il la qualifie, pour savoir comment, quand et où le peuple utilise le droit, les institutions juridiques ou les procédures juridiques. Le déploiement de l'idée de culture juridique dans un abord descriptif facilitait aussi les dialogues avec l'Anthropologie ou, sur un autre registre encore, permettait de renouveler les développements autour du pluralisme juridique.

Dans le cadre des débats revivifiés des années 1990, les critiques ne tarderont pas à arriver, notamment à l'intérieur de la Sociologie du droit, portant en particulier sur l'indétermination de la notion, et notamment d'un mécanisme causal qui resterait trop vague. ${ }^{5}$ En dépit de ces résistances empiriques, ou en partie grâce à elles, ${ }^{6}$ le concept semble avoir gardé une portée heuristique, et même critique, considérable, en particulier à l'intérieur du Droit comparé, dans la mesure où il permet d'échapper à la réduction du droit à la textualité des normes positives et des décisions jurisprudentielles, notamment nationales_-pas de droit comparé, pourrait-on dire au vu des développements des trois dernières décennies, sans appel à la culture juridique. $^{7}$

Travailler avec l'idée de culture juridique suppose pourtant des opérations de distinction de sens assez poussées, comme en semblent être d'accord défenseurs et détracteurs de la notion. L'entreprise doit commencer par la distinction analytique entre deux aspects, certes, liés, l'affirmation du droit comme produit culturel, d'une part, et l'idée de «culture juridique», d'autre part. En effet, le droit apparaît comme une pratique culturelle, y compris dans son caractère productif, constitutif de toute

\footnotetext{
3 Friedman [10, 11].

4 Blankenburg, Bruinsma [7, p. 13].

5 Cotterrell [9]. En partant de la critique des conceptions de L. Friedman, il estime que les difficultésendémiques-limitent l'utilité du concept pour une sociologie du droit, privilégiant le concept d'idéologie juridique [9, pp. 88-89]. Dans sa réponse, L. Friedman soutiendra que le caractère vague du concept et les obstacles pour le définir ne sont pas plus grande que celles d'autres concepts des sciences sociales (Friedman [12, p. 33]).

${ }^{6}$ Pour Cotterrell [9, p. 95]: «the concept is most useful for its emphasis on the sheer complexity and diversity of the social matrix in which contemporary state legal systems exist», mais il rendrait difficile l'identification d'une culture juridique spécifique.

7 «La culture est ce qui permet de marquer l'identité d'un système juridique et donc sa différence par rapport aux autres systèmes»: Ponthoreau [20, p. 119]. Dans le même sens, Legrand considère que la culture serait un méta-discours dont le droit représente une application. Le discours du droit serait donc une manifestation du discours culturel, mais pas son reflet [16, pp. 229-230].
} 
culture. Ces dernières années, dans le domaine du Droit constitutionnel allemand en particulier, nous avons vu un projet très vigoureux de définir à nouveaux frais le droit comme culture et la science du droit comme science culturelle. ${ }^{8}$

Le concept de «culture juridique» implique, certes, que le droit est un produit culturel, mais l'assertion semble renfermer une double signification. D'une part, comme l'écrivait L. Friedman, la culture juridique ferait référence à des «ideas, values, expectations and attitudes towards law an legal institutions, which some public or some part of public holds» dans un sens qu'il appellera externe. ${ }^{9}$ Ainsi, la culture juridique peut se présenter comme un ensemble de conceptions, de représentations et de modes d'action, conscients ou inconscients des acteurs d'un système juridique, qui s'inscrivent dans une certaine durée, et qui lui permettent de produire des valeurs, des normes, des institutions. ${ }^{10}$ Nous pourrions alors identifier une culture juridique $(\mathrm{x})$, dont les traits seraient différents de ceux de la culture juridique (y), etc.

D'autre part, «culture juridique» serait un méta-concept qui nous permettrait d'identifier une série de pratiques, discours, concepts comme étant ou faisant partie d'une culture juridique déterminée (nationale avant tout, mais aussi régionale, actuelle ou historique, et partant, savante, populaire, technique, etc.). En ce sens, la culture juridique serait «one way of describing relatively stable patterns of legally oriented social behavior and attitudes». ${ }^{11}$ Dans cette perspective, elle apparaît comme une expression particulière de l'analyse culturelle appliquée au droit, pas la culture du droit.

A la fois identifiant et identifié, le caractère complexe du concept serait donc constitutif. Dès lors, on peut être d'accord avec D. Nelken lorsqu'il affirme que le concept de culture juridique est un «terme hybride», qui le conduit à insister sur ses usages davantage que sur sa définition. ${ }^{12}$ Toutefois, un débat spécifique semble donner des pertinences différentes à ces emplois selon la discipline car, comme l'indique une spécialiste: «although the potential of the concept to bring together the 'legal' and 'social' has been recognised at the theoretical level by specialists in comparative studies, its practical use in empirical research remains very poor». ${ }^{13}$

Dans tous les cas, l'appel au concept de «culture juridique» suppose déjà de déborder la perspective d'une «conscience juridique», même si l'idée de mentalité et encore celle de croyance ne lui sont pas étrangères-mais c'est leur inscription dans une histoire et dans une pratique, qui permet de les concevoir comme «culture». La

\footnotetext{
8 Nous pensons à l'œuvre, encore peu connue en France, de Häberle [13].

9 L. Friedman [12, p. 34]. Il avait identifié, à côté, une signification interne, qui fait référence à «the legal culture of those members of society who perform specialized legal tasks» (Friedman [11, p. 223]). Ce groupe partage donc un ensemble de représentations, raisonnements, idéologies, valeurs, qui façonnent aussi bien leurs propres conduites que celles des acteurs non professionnels, notamment par le langage juridique.

${ }^{10}$ Voir Bell [5, pp. 247-248]. Il insiste sur la double dimension, idéaliste et pratique, de la culture juridique.

11 Nelken [18, p. 1].

12 Voir Nelken [17, p. 439] et surtout, avec une discussion d'ensemble, Nelken [19].

13 M. Kurkchiyan, «Comparing Legal Cultures: Three Models of Court for Small Civil Cases», cité in Nelken [19, p. 3].
} 
spécificité du juridique n'est pas moins grande: pour certains auteurs, comme E. Blakenburg «there may be many normative expectations of the general public, but there is no legal culture outside existing legal institutions». ${ }^{14}$

En même temps, si ce rapport aux institutions est constituant, un système juridique n'implique pas une unique culture juridique: la culture juridique a en soi, comme il est toujours souligné par les tenants du concept, un caractère multilayered, «multiforme», etc. ${ }^{15}$ On peut en effet penser que la culture juridique d'un système juridique donné implique toujours plusieurs strates, depuis la culture juridique savante à la culture juridique populaire, à condition d'être conscients que l'on est plus près de l'enchevêtrement que dans la superposition. ${ }^{16}$ Et même une culture juridique «interne» offre plusieurs facettes différentes, comme la culture universitaire, la culture judiciaire, la culture professionnelle des avocats, etc., bien que ne se plaçant pas au même niveau.

Le type de rapport entre institution positive et culture juridique doit toujours être précisé, car son caractère n'est pas le même que celui qu'entretient par exemple la doctrine juridique à son égard. Il touche notamment à un autre problème spécifique: la question de la temporalité, de la permanence mais aussi du déclin d'une culture juridique. ${ }^{17}$ Celle-ci n'est pas calquée sur la temporalité des institutions, et d'ailleurs la permanence des éléments anciens peut se retrouver dans des nouvelles reconfigurations culturelles, à côté des composantes novatrices. Si cette détermination intéresse moins les appropriations sociologiques du concept, elle peut être nécessaire pour déterminer les évolutions d'une culture juridique donnée.

Pour être opératoire, néanmoins, une culture juridique doit être «codifiée» dans l'esprit de ses acteurs, même si les degrés de cette mise en forme peuvent varier dans un continuum, depuis un niveau de constitution fort (ces grands codificateurs que sont les facultés de droit et notamment la doctrine) à des niveaux moins structurés (les individus, une classe sociale, des syndicats, la société).

Si l'on se place d'un point de vue statique, on s'apercevra que la culture juridique est donc formée de plusieurs strates (philosophique, politique, historique, savante, professionnelle, etc.), et chacune d'elles peut être privilégiée, à condition ne pas perdre de vue les autres facettes les entourant. Mais il y a aussi une autre dimension centrale, que l'on aperçoit en empruntant une perspective dynamique, qui nous révèle le caractère changeant, évolutif, de toute culture juridique-le trait qui permet de la distinguer le mieux d'ailleurs de ce concept voisin de «tradition juridique». Ce caractère dynamique semble s'accentuer quand on pense que non seulement un même système juridique peut renfermer plusieurs «cultures» juridiques différentes, mais elles peuvent être encore en opposition, ou du moins

\footnotetext{
${ }^{14}$ Cf. Blankenburg [8, p. 65]. En ce sens, il affirme que «Legal culture is as much the product of the system as it is its generator».

${ }^{15}$ Blankenburg, Bruinsma [7]. Pour Blankenburg [8, pp. 47-48] le concept combine trois niveaux: celui du droit substantif et des codes procéduraux, celui des institutions comme les cours et les professions légales, et celui des conduites juridiques et des attitudes envers le droit.

${ }^{16}$ Legrand [16, pp. 232-233].

${ }^{17}$ La question est introduite notamment chez les historiens travaillant sur la culture politique (Berstein [6]). Cependant elle se pose de manière différente dans la culture juridique: sur le problème de la temporalité en droit, Herrera [14].
} 
en tension. D'ailleurs, la vieille distinction de Raymond Williams entre culture dominante, culture résiduelle et culture émergeante, et surtout le rapport temporel qu'entretienne la première avec ces deux formes alternatives de culture, garde sa pertinence pour approcher le concept d'un point de vue juridique. ${ }^{18}$

Les études qu'on lira dans ce volume assument, à des degrés diverses, les complexes dimensions de la notion, mais privilégient un angle particulier: le rapport culture juridique/politique. Il ne s'agit pas seulement d'illustrer la composante politique de toute culture juridique, mais d'analyser aussi la portée que peut avoir une culture juridique dans l'espace politique. Il semble opportun, d'une manière générale, d'observer comment la culture juridique que l'on peut qualifier d' «interne», c'est-à-dire conçue comme un discours des juristes, se déploie et est utilisée à des visées qui ne sont pas uniquement «juridiques». Surtout, que la réappropriation de ce discours à des fins politiques produit des effets spécifiques dans la propre culture juridique.

La mise en rapprochement semble d'autant plus intéressante si l'on accepte, ne serait-ce qu'à titre d'hypothèse historique, que les différents acteurs politiques nationaux s'approprient davantage que par le passé le discours du droit et des droits, ${ }^{19}$ une grammaire qui produit des effets politiques spécifiques. Cette sorte de culture juridique des droits, dans sa double dimension interne et externe, nous permettra d'observer ce qui a de juridico-culturel dans un espace politique (par exemple, la place de la justice constitutionnelle dans certains systèmes politiques) ou social (l'action d'un syndicat ou d'une ONG).

Les articles qui forment le dossier s'arrêtent sur des cas nationaux divers. Nous avons essayé d'échapper à un premier écueil: réduire la notion à la culture juridique «occidentale», ou du moins être très attentifs à sa transmutation lors qu'on s'éloigne des rivages européens. Le politique est aussi décliné au pluriel: il peut s'incarner dans une théorie, dans la construction d'un État national, dans la promotion d'un ensemble de valeurs, ou encore dans un mode d'intervention concret sur l'arène sociale.

Eduardo Zimmermann insiste sur l'importance des «transferts» dans la constitution d'une culture juridique. Son analyse porte sur l'émergence du droit public en Argentine, à cheval entre le $\mathrm{XIX}^{\mathrm{e}}$ et le $\mathrm{XX}^{\mathrm{e}}$ siècle. En effet les cultures juridiques latino-américaines peuvent être perçues comme une «création globale». S'il se focalise sur la culture savante des professeurs et juristes-en s'appuyant sur la distinction de Friedman, devenue classique-, il privilégie l'identification d'une circulation complexe, qui passe par plusieurs voies (l'édition, les visites, etc.), ne se limitant pas à la simple reproduction d'idées. D'ailleurs, on serait devant une culture mélangée (mixed).

Le deuxième article partage la même aire culturelle, puisqu'il porte sur le Brésil, et le point de départ historique, même si les auteurs remontent leur analyse à la colonisation, tout en la prolongent jusqu'à nos jours. L'exception apparaît ici comme l'élément constitutif de cette culture juridique brésilienne, dont la

\footnotetext{
${ }^{18}$ En français, v. Williams [21, pp. 40-42]. Pour une application en droit, v. l'article pionnier de Baxi [4].

${ }^{19}$ Cf. Herrera [15].
} 
normativité, dans sa prétention à l'abstraction et à la généralité, serait, sinon absente, du moins étrangère. La domination-l'élément proprement politique de cette culture juridique de l'exception-est placée au centre de l'analyse.

Un aspect central de la culture juridique est mis en relief par l'étude de Leila Choukroune sur la Chine: son caractère mouvant, évolutif. Son travail explore en effet la tension entre les attentes de la population après l'adoption d'un ensemble des règles juridiques (constitutionnelles, mais aussi dans d'autres matières plus proches de la vie quotidienne, comme le droit de propriété ou le droit du travail), et la volonté du Gouvernement de maintenir un ordre étatique non pluraliste. Cette politique du droit ne signifie pas la fin de tout droit, mais plutôt l'émergence d'un droit autre, disciplinaire, qui serait l'expression de cette tension.

Le problème de la culture constitutionnelle revient de manière centrale dans l'essai d'Agostino Carrino, qui porte encore sur l'actualité. Mais la portée du discours de droits fondamentaux change ici: il est approché comme faisant partie d'une culture constitutionnelle italienne particulière, dont l'auteur voit prendre les traits d'une théologie des droits. Ici, la culture juridique est tout près du politique, car il n'y a pas de supra-historicité des constitutions, et donc du droit constitutionnel, puisque toute constitution est le résultat d'un conflit, qui est réglé à partir de la conception et les forces sorties victorieuses. Cette transformation de la culture juridique italienne ne pourrait pas se comprendre en dehors du contexte de la mondialisation et le projet d'inspirer confiance chez les individus dans un monde devenu «dangereux».

Ce rapport au politique est exploré dans une perspective plus abstraite par María Isabel Garrido Gómez, qui se penche sur la culture juridique que sous-entendent les théories démocratiques occidentales, notamment à propos du problème de la crise de la représentation. Les explications fondées sur les changements dans la fonction et la structure de l'État supposent une vision relativement stable de la culture juridique. Mais la théorie de la démocratie ne peut pas se passer de cette dimension juridique, en dépit du fait que les conceptions récentes s'engagent d'une autocompréhension procédurale de la démocratie par la délibération, puisque les règles, établissant limites et incompatibilités, ont fait de la démocratie des systèmes juridiques au sens fort (sans les limiter pour autant à la loi, et sans ignorer que l'Exécutif est l'acteur central). En ce sens, le pluralisme n'est pas suffisant pour concevoir la démocratie.

Nous mettions un point final à cette introduction quand nous est parvenu la nouvelle de la mort d'André-Jean Arnaud, le 25 décembre dernier. Depuis longtemps, il avait placé la question de culture juridique au centre de ses préoccupations, car «la perception culturelle de la pensée juridique relativise le phénomène juridique, amène l'observateur à penser le droit au pluriel». ${ }^{20}$ Mais il a aussi œuvré tout aussi intensément pour faire dialoguer les différentes cultures juridiques et ce n'est pas un hasard si le Dictionnaire encyclopédique de théorie et de sociologie du droit, qu'il a dirigé, fait côtoyer, après l'entrée générale «culture juridique», des articles sur les cultures juridiques africaine, chinoise, juive, d'Océanie ... C'est à sa mémoire que ce court texte est dédié.

${ }^{20}$ Voir Arnaud [2, p. 23]. 


\section{References}

1. Alland, Denis, and Rials, Stéphane (dir.). 2003. Dictionnaire de la culture juridique. Paris: PUF Lamy.

2. Arnaud, André-Jean. 1991. Pour une pensée juridique européenne. Paris: PUF.

3. Arnaud, André-Jean (dir.). 1993. Dictionnaire encyclopédique de théorie et de sociologie du droit, 2nd ed. Paris: LGDJ.

4. Baxi, Upendra. 1991. The conflicting conceptions of legal culture and the conflicts of legal cultures. Journal of Indian Law Institute 33: 173-188.

5. Bell, Joshua. 2009. De la culture. In Comparer les droits, résolument, Pierre Legrand (dir.). Paris: PUF.

6. Berstein, Serge. 2003. Nature et fonctions des cultures politiques. In Les cultures politiques en France, S. Berstein (dir.). Paris: Seuil.

7. Blankenburg, Erhard, and Freek Bruinsma. 1994. Dutch legal culture. Deventer et Boston: Kluwer.

8. Blankenburg, Erhard. 1997. Civil litigation rates as indicators for legal culture. In Comparing legal cultures, D. Nelken (dir.). Dartmouth.

9. Cotterrell, Roger. 2006. The concept of legal culture. In Law, culture and society. Legal ideas in the mirror of social theory, Aldershot: Ashgate.

10. Friedman, Lawrence. 1969. Legal culture and social development. Law and Society 4(1): $29-44$.

11. Friedman, Lawrence. 1975. The legal system. A social science perspective. New York: Russel Sage Foundation.

12. Friedman, Lawrence. 1997. The concept of legal culture: A reply. In Comparing legal cultures, D. Nelken (dir.). Aldershot: Dartmouth.

13. Häberle, Peter. 1998. Verfassungslehre als Kulturwissenschaft, 2nd ed. Berlin: Duncker \& Humblot.

14. Herrera, Carlos-Miguel. 2012. Variation, évolution, métamorphose: les significations du concept de constitutionnalisme. In Variation, évolution, métamorphose, B. Pouderon, J. Casas (dir.). Saint Etienne: Presses Universitaires.

15. Herrera, Carlos-Miguel. 2014. Entre droit constitutionnel et démocratie: les contre-pouvoirs sociaux. In La démocratie, mais qu'en disent les juristes, A. Viala (dir.). Paris: LGDJ.

16. Legrand, Pierre. 2009. La comparaison des droits expliquée à mes étudiants. In Comparer les droits, résolument, P. Legrand (dir.). Paris: PUF.

17. Nelken, David. 1995. Understanting/invoking legal culture: An introduction. Social and Legal Studies 4: 435-452.

18. Nelken, David. 2004. Using the concept of legal culture. Australian Journal of Legal Philosophy 29: $1-26$.

19. Nelken, David. 2012. Using legal cultures: Purpose and problems. In Using Legal Culture, D. Nelken (dir.). Londres: Wildy, Simmonds and Hill Publishing.

20. Ponthoreau, Marie-Claire. 2010. Droit(s), constitionnel(s) comparé(s). Paris: Economica.

21. Williams, Raymond. 2009. Culture and matérialisme. Paris: Les prairies ordinaires. 